\title{
VIX Futures ETNs: Three Dimensional Losers
}

\author{
G.D. Hancock ${ }^{1}$ \\ ${ }^{1}$ Associate Professor of Finance, College of Business Administration, University of Missouri-St. Louis, 1 University \\ Blvd. T-1112, St. Louis, MO 63121, USA \\ Correspondence: G.D. Hancock, Associate Professor of Finance, College of Business Administration, University of \\ Missouri-St. Louis, 1 University Blvd. T-1112, St. Louis, MO 63121, USA. Tel: 1-314-607-5949. Fax: \\ 314-516-6420. E-mail: gdweise@umsl.edu
}

Received: June 6, 2013

Accepted: June 242013

Online Published: June 27, 2013

doi:10.5430/afr.v2n3p53

URL: http://dx.doi.org/10.5430/afr.v2n3p53

\begin{abstract}
This research tests the performance of volatility Exchange Traded Notes (ETN) and Funds and compares the results to three benchmarks to determine whether the risk-adjusted returns are sufficient to compensate for the high risk and high expenses. Two tests are composed along three dimensions to establish the magnitude and frequency with which the volatility funds outperform the benchmarks. The first dimension tests the robustness of the fund performance to the construction of the portfolio. The results provide evidence that the strong negative correlation between the S\&P 500 and ETN returns is not sufficient to consistently produce risk-adjusted returns greater than the benchmarks. The second dimension tests the sensitivity of the results to one-day, one-week and one-month holding periods. The findings indicate that changes in the holding period alter the identity of the successful portfolios but the number of successful funds remains low regardless of the holding period. Finally, the third dimension employs two different weighting methods to the construction of the portfolios. Once again, the findings show that the number of successful portfolios produced by either weighting method is low and unimpressive relative to the benchmarks. Overall, the evidence suggests that the poor performance is unique to volatility ETNs rather than to volatility in general.
\end{abstract}

Keywords: ETNs, ETFs, VIX, Volatility, VIX futures, VIX portfolio weights

\section{Introduction}

The proliferation of VIX-based products, designed to provide investors with tools for managing volatility, raises questions as to their ability to do so. This research tests the performance of one category in the growing product list: volatility Exchange Traded Notes (ETNs) and Funds (ETFs). Specifically, the population of nine long volatility ETNs and three volatility ETFs is tested using risk-adjusted returns to standardize the comparison of each portfolio's parameters to three benchmarks including the S\&P 500, a base portfolio and a null strategy. In the fall of 2012, seven long volatility ETNs ceased trading due to lack of investor interest and are, therefore, not included in this analysis.

Regardless of the facet evaluated, volatility exchange traded funds and notes do not provide risk-adjusted returns (RARs) which consistently outperform the benchmarks. (Note 1) The S\&P 500 is either the total return index or the excess return index depending on the fund's strategy as identified in Table 1. The base portfolios are tailored to mirror the fund's objective and consists of a core long position invested directly in 1-2 month maturity VIX futures (Base ${ }_{\mathrm{st}}$ ), or 3-4 month maturity (Base $\mathrm{md}_{\mathrm{d}}$ ), combined with a long position in the S\&P 500. The null strategy equates to no investment resulting in a zero RAR.

Two tests are composed along three dimensions. Test 1 measures the fraction of time periods when the RARs for each fund exceeds the S\&P 500. Test 2 compares the average risk-adjusted return (ARAR) for each fund to the ARAR for each benchmark.

The three dimensions examined are:

1. Portfolio Construction. The 12 funds are tested as individual portfolios (IPs) and then re-tested when combined with the S\&P 500 to form 12 constructed portfolios (CPs). A total of 24 portfolios are evaluated.

2. Time Sensitivity. The performance of the IPs and CPs is tested under one-day, one-week and one-month holding periods.

3. Portfolio Weighting. The CPs are tested using two different weighting methodologies: the Unit Change and the White Noise Beta. 
The goal is to determine whether the performance of volatility ETN portfolios is sufficient to compensate for the higher risk and higher expenses relative to the benchmarks. The three dimensions serve to determine the robustness of the test results.

The first volatility ETN, i-Path's VXX, was offered on January $29^{\text {th }}, 2009$ and most recently the UVXY ETF was issued by ProShares on October $4^{\text {th }}, 2011$. This study does not encompass inverse funds which allow investors to take a bearish stance on volatility. Even so, eleven such funds have been offered since August 2010, underscoring the rapid expansion of volatility products.

Each long volatility fund purports a slightly different salable feature as shown in Table 1. Some funds offer short-term VIX futures exposure of 1-2 month while others offer mid-term exposure of 3-4 months. Five of the funds track the S\&P 500 VIX Futures Total Return Index, one fund tracks the Citi Volatility Total Return Index and the remaining six funds track the $S \& P 500$ VIX Futures Excess Return Index as identified in Table 1. None of the funds are based on the VIX; instead, they are based on VIX futures, which behave differently than the VIX, making the distinction important for investors. It is noteworthy, that management expense ratios are generally fairly high for volatility funds, ranging from $0.89 \%-1.65 \%$, compared to other types of ETNs which average $0.5 \%$.

Table 1. ETF and ETN characteristics

\begin{tabular}{lllllll}
\hline Ticker & \multicolumn{1}{c}{ Strategy* } & \multicolumn{1}{c}{ Sponsor } & Inception & $\begin{array}{c}\text { Expense } \\
\text { Ratio }\end{array}$ & $\begin{array}{c}\text { Mkt.Cap. } \\
\text { (millions) }\end{array}$ & \multicolumn{1}{c}{$\begin{array}{c}\text { Daily } \\
\text { Volume }\end{array}$} \\
\hline CVOL & VIX Mid-Term TR ETN & C-Tracks & $11 / 15 / 2010$ & $1.15 \%$ & $\$ 4.03$ & 17,376 \\
TVIX & 2X VIX Short-Term ER ETN & VelocityShares & $11 / 30 / 2010$ & $1.65 \%$ & $\$ 322.73$ & $5,819,375$ \\
TVIZ & 2X VIX Mid-Term ER ETN & VelocityShares & $11 / 30 / 2010$ & $1.65 \%$ & 4.67 & 6,761 \\
UVXY & VIX Short-Term ER ETF & ProShares & $10 / 4 / 2011$ & $1.41 \%$ & 291.17 & 455,256 \\
VIIX & VIX Short-Term ER ETN & VelocityShares & $11 / 30 / 2010$ & $0.89 \%$ & $\$ 68.29$ & 114,500 \\
VIIZ & VIX Mid-Term ER ETN & VelocityShares & $11 / 30 / 2010$ & $0.89 \%$ & $\$ 7.78$ & 968 \\
VIXM & VIX Mid-Term TR ETF & ProShares & $1 / 3 / 2011$ & $0.85 \%$ & $\$ 112.40$ & 32,600 \\
VIXY & VIX Short-Term TR ETF & ProShares & $1 / 3 / 2011$ & $0.85 \%$ & $\$ 168.12$ & 362,673 \\
VXX & VIX Short-Term TR ETN & i-Path & $1 / 29 / 2009$ & $0.89 \%$ & $\$ 1,660.00$ & $16,534,572$ \\
VXZ & VIX Mid-Term TR ETN & i-Path & $2 / 20 / 2009$ & $0.89 \%$ & $\$ 250.56$ & 396,809 \\
XVIX & Long-Short VIX ER ETN & ETRACS & $12 / 1 / 2010$ & $0.85 \%$ & 23.13 & 17,703 \\
XVZ & Dynamic VIX TR ETN & i-Path & $8 / 18 / 2011$ & $0.95 \%$ & 273.22 & 30,235 \\
\hline Average & & & & $\mathbf{1 . 0 0 \%}$ & $\mathbf{\$ 1 6 9 . 4 8}$ & $\mathbf{1 , 2 5 3 , 5 9 4}$ \\
\hline
\end{tabular}

"TR $=$ Total Return, ER = Excess Return, ETN $=$ Exchange Traded Note, ETF $=$ Exchange Traded Fund.

There is no theoretical basis which leads to an expectation for different performance between the ETNs and ETFs. However, ETNs differ significantly from ETFs in several aspects. Unlike ETFs, ETNs incur no interest or dividend distribution which means there is no tax on income. In addition, ETNs do not have an upper limit on the maximum asset allocation to a single product as do ETFs. Contrasting with other buy-and-hold structured products, ETNs can be bought and sold during normal trading hours on an exchange. For institutional investors, ETNs can be offered for repurchase on a weekly basis. In this sense, ETNs are structured to resemble ETFs. Even so, ETNs are debt instruments with cash flows derived from the performance of an underlying structured asset.

The issuance of ETNs does not imply an expansion of equity, although they trade like stock. Instead, ETNs are an innovative way for institutions to borrow which does not require them to guarantee the return of any principal upon maturity. As debt instruments, ETNs are subject to the risk of default by the issuer. This is a key difference between ETFs and ETNs: ETFs are subject only to market risk whereas ETNs are subject to both market risk and the default risk of the issuer. Even though the possibility of default turning into a reality is relatively low, recent experience with major financial institution failures indicates that it ought to be accounted for and measured. 
In light of the issues raised, each portfolio is evaluated to determine whether the risk-adjusted returns are sufficient to compensate investors for the high risk and high expenses relative to the benchmarks. The empirical evidence relating to VIX futures and volatility ETNs as effective instruments for diversification follows three threads of interest to the dimensions tested.

The strong negative correlation between the VIX and VIX futures relative to equity returns lends credence to the idea that adding volatility as an asset class can produce higher risk-adjusted returns. Practitioners and researcher alike have noted the strong negative relationship between VIX products and equity returns. Daigler and Rossi (2006) demonstrate, using a Markowitz portfolio of stocks, that adding volatility to an S\&P 500 stock portfolio substantially reduces risk without having a significant impact on return. They argue that, in spite of the large daily volatility in the VIX, the high negative correlation between the VIX and the S\&P 500 creates an opportunity to combine stocks with a volatility asset that significantly reduces portfolio risk compared to the S\&P 500 portfolio. Liu and Dash (2012) show that volatility ETNs have a similar negative correlation profile with the equity markets. In addition, ETNs exhibit the same directional hedge and portfolio diversification properties as does the spot VIX. However, they also note that the beta of these indices with VIX is much less than 1, which results in moves of lower magnitude than spot VIX. They note significant roll losses, ranging from $0.07 \%$ to $0.18 \%$ per day, associated with holding these instruments. Krein and Fernandez (2012) argue that the success of easily traded volatility index products is due to the significant reduction in portfolio risk while not sacrificing performance.

In fact, establishing a long position in the S\&P 500 and a long position in any other asset which is not perfectly correlated is likely to produce frequent superior results to holding the S\&P alone. A portfolio with only one long exposure, compared to one with two long exposures, is an incremental step that provides an opportunity for finding multiple strategies that can outperform the single S\&P 500 exposure portfolio over a specific time period.

Moran and Dash (2007) confirm similar diversification benefits as Daigler and Rossi, adding a noted negative correlation between hedge fund returns and the VIX. They show that the correlation profile is asymmetric, with the correlation being more negative in negative months for hedge funds. The diversification benefit is shown to be best when hedge funds are delivering the worst quartile returns.

A strong negative correlation is observed in each of the twelve CPs evaluated in this research, averaging -0.4828 , suggesting that the CPs should result in higher risk-adjusted returns than the S\&P 500 held alone.

A second thread of research of relevance relates to the appropriate holding period. Goldwhite (2009), Rhodes (2011) and Wang and Daigler (2011), have found evidence of a mean reverting tendency of the VIX over the long-term. According to Rhodes, in spite of the mean reverting behavior of VIX and VIX products, the implied volatility measures can still reach levels well above the mean and exhibit high variability. This body of research implies that holding VIX futures over a long time period is counter-productive as the mean return will be zero. Alexander and Korovilas (2012) state that the most common holding periods are one-week and one-month. However, fund sponsors recommend a holding period as short as one-day.

The final research thread of interest concerns the optimal weights applied to volatility products when combined with equity. There is little published research directly addressing this issue, however, Dash and Moran (2005) explore the relationship between the VIX index and hedge fund returns and find that, using standard mean variance analysis, the optimal allocation of the VIX index in efficient portfolios is less than $10 \%$. Alternatively, Dennis, Mayhew and Stivers (2006) conduct a hypothetical exercise to assess the diversification benefit derived from including VIX in a multi-asset portfolio. They examine the effects of incorporating increasing allocations to VIX in a typical balanced $(60 / 40)$ stock/bond portfolio. Using the returns and volatility characteristics of the VIX, which is not directly investable, they find a clear benefit, in terms of both risk and reward, accrues when allocating to VIX as part of their overall portfolio. Daigler and Rossi (2006) weight volatility by applying the previous year's optimal portfolio weights. They find that this generates a portfolio of stocks plus volatility that is almost identical to the optimal minimum risk portfolio.

Academic researchers appear to agree that volatility can be an important addition to an equity portfolio under certain circumstances. Much of the research to date has covered the VIX, VIX futures and VIX options with less attention focused on the increasingly available array of ETNs and ETFs.

\section{Data and Methodology}

Daily data, from the inception of each fund (Table 1), is analyzed for the 12 volatility ETFs, the S\&P 500 total return index, the S\&P 500 excess return index and 1-4 month maturity VIX futures contracts. The VIX futures contracts are used to constructed two base portfolios which approximate the investment objectives of each fund. For example, if 
the fund's exposure is 1-2 month maturity VIX futures and the S\&P 500 total return index, then the base portfolio is constructed likewise. The one exception is the XVZ Dynamic VIX strategy. This fund is a mix of both short-term and mid-term exposures determined by monitoring the steepness of the implied volatility curve. The specific strategy employed is not publicly available and therefore could not be replicated. Instead, the performance of XVZ is compared to the average of the performance of the short-term base, Base $\mathrm{st}_{\mathrm{s}}$, and the mid-term base, Base $_{\mathrm{md}}$, portfolios. Constructing various average maturities is fairly straight-forward because the CBOE maintains a set of futures contracts on the VIX expiring each month for the next nine months.

The existence of transactions costs will alter the risk-adjusted returns of the ETNs and the VIX futures positions. For ETNs there are two costs to consider: the cost of buying or selling and the cost of holding the position (i.e. the Management Expense). For a VIX futures position there is only the cost of buying or selling to consider. However, this trading cost will most likely be higher than the trading cost associated with the ETNs because the investor will be required to make the transactions necessary to maintain a given maturity. It is assumed throughout that the trading cost required to maintain a desired maturity in the VIX futures position is equal to the Management Expense Ratio of the associated ETN. This assumption implies transactions costs and management expenses to drop from the analysis since the impact on both positions is the same.

The RAR for each individual portfolio, $\mathrm{RAR}_{\mathrm{i}, \mathrm{t}}$, constructed portfolio, $\mathrm{RAR}_{\mathrm{pi}, \mathrm{t}}$, base, $\mathrm{RAR}_{\mathrm{j}, \mathrm{t}}$, the $\mathrm{S} \& \mathrm{P} 500, \mathrm{RAR}_{\mathrm{sp}, \mathrm{t}}$, and the null strategy, $\mathrm{RAR}_{\mathrm{n}, \mathrm{t}}$, is measured over one-day, one-week and one-month holding periods as follows:

$$
\operatorname{RAR}_{\mathrm{p}, \mathrm{t}}=\frac{\mathrm{R}_{\mathrm{p}, \mathrm{t}}}{\sigma_{\mathrm{p}, \mathrm{t}}}
$$

The returns and standard deviations for the portfolios are described by an application of the Markowitz approach as identified in equations 2 and 3 below:

$$
\begin{gathered}
\mathrm{R}_{\mathrm{p}, \mathrm{t}}=\mathrm{W}_{\mathrm{sp}, \mathrm{t}} x \mathrm{R}_{\mathrm{sp}, \mathrm{t}}+\mathrm{W}_{\mathrm{i}, \mathrm{t}} x \mathrm{R}_{\mathrm{i}, \mathrm{t}} \\
\left.\sigma_{\mathrm{p}, \mathrm{t}}=\mathrm{W}_{\mathrm{sp}, \mathrm{t}}^{2} \mathrm{x} \sigma_{\mathrm{sp}, \mathrm{t}}^{2}+\mathrm{W}_{\mathrm{i}, \mathrm{t}}^{2} \mathrm{x} \sigma_{\mathrm{i}, \mathrm{t}}^{2}+2 \mathrm{x} \rho_{\mathrm{spt,it}} \mathrm{x} \sigma_{\mathrm{sp}, \mathrm{t}} \mathrm{x} \sigma_{\mathrm{i}, \mathrm{t}} \mathrm{xW} \mathrm{W}_{\mathrm{sp}, \mathrm{t}} \mathrm{xW} \mathrm{W}_{\mathrm{i}, \mathrm{t}}\right]^{1 / 2}
\end{gathered}
$$

The variables are defined as:

$$
\begin{aligned}
& \mathrm{RAR}_{\mathrm{p}, \mathrm{t}}=\text { The risk-adjusted return for the IP, CP, core or base portfolio over time period } t \text {; } \\
& \mathrm{R}_{\mathrm{p}, \mathrm{t}}=\text { The return on the IP, CP, or base portfolio over time period } t \text {; } \\
& \mathrm{R}_{\mathrm{sp}, \mathrm{t}}=\text { The return on the } \mathrm{S} \& \mathrm{P} 500 \text { over the time period } t \text {; } \\
& \mathrm{R}_{\mathrm{i}, \mathrm{t}}=\text { The return on the } i^{\text {th }} \text { ETN or the } j^{\text {th }} \text { core long VIX futures position over time period } t \text {; } \\
& i=1,2,3, \ldots 12 \text { and } j=\text { Base }_{\mathrm{st}}, \text { Base }_{\mathrm{md}} \text {; } \\
& \mathrm{W}_{\mathrm{sp}, \mathrm{t}}=\text { The percentage invested in the S\&P } 500 \text { at the beginning of time period } t \text {; } \\
& \mathrm{W}_{\mathrm{i}, \mathrm{t}}=\text { The percentage invested in the } i^{\text {th }} \text { ETN or for the } j^{\text {th }} \text { core VIX futures position at the beginning of } \\
& \text { time period } t \text {; } \\
& \sigma_{\mathrm{p}, \mathrm{t}}=\text { The standard deviation of returns for the portfolio, measured over the previous } \\
& 22 \text { trading days, as of time } t \text {; (Note 2) } \\
& \sigma_{\mathrm{sp}, \mathrm{t}}=\text { The standard deviation of returns for the S\&P 500, measured over the previous } \\
& 22 \text { trading days, as of time } t \text {; } \\
& \sigma_{\mathrm{i}, \mathrm{t}}=\text { The standard deviation of returns for the } i^{\text {th }} \text { ETN or the } j^{\text {th }} \text { core VIX futures position, measured } \\
& \text { over the previous } 22 \text { trading days, as of time } t \text {; } \\
& \rho_{\mathrm{sp}, \mathrm{it}}=\text { The correlation of returns between the S\&P } 500 \text { and the } i^{\text {th }} \text { ETN or the } j^{\text {th }} \text { core futures } \\
& \text { position measured over the previous } 22 \text { trading days, as of time } t \text {. }
\end{aligned}
$$

Equations (2) and (3) reduce to $\mathrm{R}_{\mathrm{i}, \mathrm{t}}$ and $\sigma_{\mathrm{i}, \mathrm{t}}$ when an IP, or core VIX futures position, is evaluated because the amount invested in the S\&P 500 is zero. As a point of clarification, note that the core is a subset of the base portfolio. The base consists of a long VIX futures position plus a long position in the S\&P 500; the core is a long position in VIX futures. The distinction is important because the core is used as the basis for comparison to the IP performance while the base is used for comparison to the CPs.

Two performance tests are applied to each portfolio. Test 1 determines the fraction, $\mathrm{F}_{\mathrm{T}}$, of days, weeks or months when the $\mathrm{RAR}_{\mathrm{p}, \mathrm{e}}$ exceeds the RAR $\mathrm{Rp}, \mathrm{t}$. Test 1 employs the following Excel command: 


$$
\mathrm{F}_{\mathrm{p}, \mathrm{T}}=\text { Countif(}\left(\mathrm{RAR}_{\mathrm{p}, \mathrm{t}}>\mathrm{RAR}_{\mathrm{sp}, \mathrm{t}}\right) / \mathrm{N} .
$$

Where $\mathrm{T}=$ day, week or month; and, $\mathrm{N}=$ total days, weeks or month.

Test 1 is applied in the exact same manner to the base portfolios, $F_{j_{, T}}$, and the null strategy, $F_{n, T}$. Test 2 first determines the ARAR for all portfolios and benchmarks and then compares each to determine portfolio success. Test 2 is represented as:

Where:

$$
\frac{\sum_{\mathrm{t}=1}^{\mathrm{N}} \mathrm{RAR}_{\mathrm{pi}, \mathrm{T}}}{\mathrm{N}}>\frac{\sum_{\mathrm{t}=1}^{\mathrm{N}} \mathrm{RAR}_{\mathrm{b}, \mathrm{T}}}{\mathrm{N}}=\operatorname{ARAR}_{\mathrm{pi,T},}>\operatorname{ARAR}_{\mathrm{b}, \mathrm{T}}
$$

$\operatorname{ARAR}_{\mathrm{pi}, \mathrm{T}}=$ average risk-adjusted return for the $i^{\text {th }} \mathrm{IP}$ or CP and $i=1,2,3 \ldots 24$;

$\mathrm{ARAR}_{\mathrm{b}, \mathrm{T}}=$ average risk-adjusted return for the ${ }^{\text {th }}$ benchmark and $=\mathrm{S} \& \mathrm{P}$, base and null.

\subsection{Portfolio Weights}

A crucial step in portfolio construction is the determination of the weights. Rather than rely on heuristic rules or an arbitrary rule of thumb, the weights are determined for each of the 12 CPs by applying the White Noise Beta (WNB) hedge and the Unit Change (UC) hedge. The application of two independent weighting designs provides insight into the robustness of the test results.

The WNB is determined using a system of three equations, in some cases more, since it is likely that returns are co-integrated with this type of security. The first equation estimates the long-run equilibrium using the form:

$$
\mathrm{R}_{\mathrm{sp}, \mathrm{t}}=\alpha_{\mathrm{o}}+\beta_{1} x \mathrm{R}_{\mathrm{i}, \mathrm{t}}+\mathrm{e}_{\mathrm{t}}
$$

The variables $\mathrm{R}_{\mathrm{sp}, \mathrm{t}}$ and $\mathrm{R}_{\mathrm{i}, \mathrm{t}}$ are rates of daily price change and are co-integrated for each of the ETNs studied. (Note 3) The OLS regression may yield asymptotically consistent estimators of the parameters $\alpha_{o}$ and $\beta_{1}$ when the variables are co-integrated. In order to determine the order of co-integration, the estimated residual sequence, $\hat{e}_{t}$ is tested for stationarity. If the deviations are found to be stationary, the $\mathrm{R}_{\mathrm{sp}, \mathrm{t}}$ and $\mathrm{R}_{\mathrm{i}, \mathrm{t}}$ series are integrated of order $(1,1)$. For each time period studied, the test, shown in equation (5), for co-integration is estimated without drift:

$$
\Delta \hat{e}_{\mathrm{t}}=\mathrm{b}_{1} \mathrm{xe}_{\mathrm{e}_{\mathrm{t}-1}}+\varepsilon_{\mathrm{t}}
$$

The variable $\hat{e}_{t-1}$ is the lagged estimated error between the fitted equation and the observed values of $R_{s p, t}$ and the variable $\Delta \hat{e}_{t}$ is the change in the error from one day to the next. The null hypothesis, $\mathrm{H}_{0}: \mathrm{b}_{1}=0$, is tested using critical values for the Engle-Granger Co-integration Test. When the null hypothesis cannot be rejected, the estimated residual series contains a unit root and $\mathrm{R}_{\mathrm{sp}, \mathrm{t}}$ and $\mathrm{R}_{\mathrm{i}, \mathrm{t}}$ are not co-integrated. The residual sequence is stationary and the series is co-integrated when the null hypothesis is rejected. Across all time periods tested and for each ETN, the residuals for this data set are found to be co-integrated.

In order to correct for the problems associated with co-integration the Engle-Granger (1987) error-correction model, described by equation (6) below, is estimated with drift.

$$
\Delta \mathrm{R}_{\mathrm{sp}, \mathrm{t}}=\alpha_{\mathrm{o}}+\sum_{\mathrm{j}=1}^{\mathrm{n}} \mathrm{b}_{1, \mathrm{j}} x \hat{\mathrm{e}}_{\mathrm{t}-\mathrm{j}}+\sum_{\mathrm{j}=1}^{\mathrm{m}} \mathrm{b}_{2, \mathrm{j}} x \Delta \mathrm{R}_{\mathrm{sp}, \mathrm{t}-\mathrm{j}}+\sum_{\mathrm{j}=1}^{\mathrm{k}} \mathrm{b}_{3, \mathrm{j}} x \Delta \mathrm{R}_{\mathrm{i}, \mathrm{t}-\mathrm{j}}+\omega_{\mathrm{t}}
$$

The errors are tested using the Durbin-Watson (1951) statistic to determine whether any serial correlation exists. When serial correlation is present, the length of the lag on the $\Delta \mathrm{R}_{\mathrm{t}-\mathrm{j}}$ variable is extended until an equation can be identified with a white noise error series. In some cases, the length of the lag on the other variables needs adjusting as well.

Once the appropriate parameter, $b_{3, j}$, is identified it is adjusted by the price ratio $\left(\mathrm{PR}_{\mathrm{i}, \mathrm{t}}\right)$ and defined as the WNB hedge ratio, $\mathrm{h}_{\mathrm{i}, \mathrm{t}}$, for the $i^{\text {th }}$ ETN in the $t^{\text {th }}$ time period. For example:

$$
h_{i, t}=b_{3, j} x P R_{i, t}
$$

Where $\mathrm{PR}_{\mathrm{i}, \mathrm{t}}=\left(\mathrm{SP}_{\mathrm{t}} / \mathrm{ETN}_{\mathrm{i}, \mathrm{t}}\right)$ and the amount invested in volatility, $\mathrm{W}_{\mathrm{i}, \mathrm{t}}$ is:

$$
\begin{aligned}
& \mathrm{W}_{\mathrm{i}, \mathrm{t}}=\frac{\mathrm{h}_{\mathrm{i}, \mathrm{t}} \times \mathrm{ETN}_{\mathrm{i}, \mathrm{t}}}{\mathrm{h}_{\mathrm{i}, \mathrm{t}} \times \mathrm{ETN}_{\mathrm{i}, \mathrm{t}}+\mathrm{SP}_{\mathrm{t}}} \\
& \mathrm{W}_{\mathrm{sp}, \mathrm{t}}=1-\mathrm{W}_{\mathrm{i}, \mathrm{t}}
\end{aligned}
$$

The frequency of the hedge revisions is one-day, one-week or one-month, depending on the holding period.

The Unit Change hedge ratio, $\mathrm{h}_{\mathrm{uc}, \mathrm{t}}$, is obtained in a straight-forward manner by taking the change in the S\&P 500 level prices divided by the change in the respective ETN prices, using the time period preceding the initiation of the hedge. Specifically, the hedge ratio is:

$$
\mathrm{h}_{\mathrm{uc}, \mathrm{t}}=\frac{\Delta \mathrm{SP}_{\mathrm{t}-1}}{\Delta \mathrm{ETN}_{\mathrm{t}-1}}
$$


The variables are defined as:

$\Delta \mathrm{SP}_{\mathrm{t}-1}=$ the change in the level of the S\&P 500 from the end of time $t-1$ to the end of time $t$; and,

$\Delta \mathrm{ETN}_{\mathrm{t}-1}=$ the change in the level of the ETN from the end of time $t-1$ to the end of time $t$.

After the hedge ratio is established, the portfolio weights are calculated by applying equations (8.a) and (8.b).

\section{Results}

This section is organized such that the performance tests for the IPs and the benchmarks are displayed in Table 2 and Table 3. The tests are then repeated for the CPs and reported in Table 4 and Table 5.

Table 2 presents the findings for Test 1, applied to the IPs, and is constructed by first comparing the RAR $\mathrm{R}_{\mathrm{i}, \mathrm{t}}$ to the $\mathrm{RAR}_{\mathrm{sp}, \mathrm{t}}$ for each day, week or month to identify the number of successful time periods. The following performance rules apply when the $\mathrm{RAR}_{\mathrm{sp}, \mathrm{t}}$ and $\mathrm{RAR}_{\mathrm{i}, \mathrm{t}}$ are both negative:

i. If the ETN portfolio has the lowest loss and the lowest risk, it is identified as outperforming the S\&P 500.

ii. If the ETN portfolio has the lowest loss (or risk) but the S\&P 500 has the lowest risk (or loss), then the magnitude of the differences in losses is compared to the magnitude of the differences in risk. The principles of risk-aversion then dictate the final decision as to which portfolio dominates.

Each day, week and month is separately evaluated and the number of successful time periods is divided by the total, $\mathrm{N}$, and the fractions are displayed in Columns 2, 4 and 6, respectively. The same procedure is followed to determine the fraction of successful time periods for the core portfolios, $\mathrm{F}_{\mathrm{j}, \mathrm{T}}$, and the null strategy, $\mathrm{F}_{\mathrm{n}, \mathrm{T}}$ relative to the $\mathrm{S} \& \mathrm{P} 500$. The bold numbers indicate an IP which outperforms the applicable core portfolio, i.e. $\quad \mathbf{F}_{\mathrm{i}, \mathrm{T}}>\mathbf{F}_{\mathrm{j}, \mathrm{T}}$, and the boxed numbers designates a fund which outperforms the S\&P 500, i.e. $\quad \mathrm{F}_{\mathrm{i}, \mathrm{T}}>\mathrm{F}_{\mathrm{sp}, \mathrm{T}}$.

Table 2. Test 1, measuring the fraction of time periods when the RARs for each fund exceeds the S\&P 500, is applied to individual portfolios

\begin{tabular}{|c|c|c|c|c|c|c|}
\hline 1 & 2 & 3 & 4 & 5 & 6 & 7 \\
\hline Fund & F(Day) & $\mathrm{N}$ & $\mathrm{F}($ Week $)$ & $\mathrm{N}$ & F(Month) & $\mathrm{N}$ \\
\hline $\mathrm{CVOL}^{* *}$ & 0.4524 & 504 & 0.3960 & 101 & 0.3200 & 25 \\
\hline TVIX ${ }^{*}$ & 0.4306 & 504 & 0.3861 & 101 & 0.3200 & 25 \\
\hline $\mathrm{TVIZ}^{* *}$ & 0.4365 & 504 & 0.4653 & 101 & 0.2400 & 25 \\
\hline $\mathrm{UVXY}^{*}$ & 0.4845 & 291 & 0.4407 & 59 & 0.0667 & 15 \\
\hline VIIX ${ }^{*}$ & 0.4226 & 504 & 0.4158 & 101 & 0.3600 & 25 \\
\hline $\mathrm{VIIZ}^{* *}$ & 0.4491 & 501 & 0.4100 & 100 & 0.2800 & 25 \\
\hline VIXM $^{* *}$ & 0.4271 & 480 & 0.5104 & 96 & 0.2917 & 24 \\
\hline VIXY* & 0.4458 & 480 & 0.5000 & 96 & 0.2500 & 24 \\
\hline VXX & 0.4224 & 966 & 0.3627 & 193 & 0.3405 & 47 \\
\hline $\mathrm{VXZ}^{* *}$ & 0.4344 & 946 & 0.4096 & 188 & 0.2826 & 46 \\
\hline $\mathrm{XVIX}^{*}$ & 0.4732 & 503 & 0.4653 & 101 & 0.3200 & 25 \\
\hline $\mathrm{XVZ}^{*, * *}$ & 0.4582 & 323 & 0.3968 & 63 & 0.1250 & 16 \\
\hline Average & 0.4447 & 542 & 0.4299 & 108 & 0.2664 & 27 \\
\hline Core $_{\text {st }}{ }^{*}$ & 0.4826 & 966 & 0.4722 & 193 & 0.3435 & 47 \\
\hline Core $_{\mathrm{md}}{ }^{* *}$ & 0.4757 & 966 & 0.4632 & 193 & 0.3421 & 47 \\
\hline Null & 0.4451 & 966 & 0.3886 & 193 & 0.3617 & 47 \\
\hline
\end{tabular}

The fractions in Table 2 are mostly less than 50\% indicating the S\&P 500 outperforms the IPs in the majority of time periods regardless of the holding period. One exception is the VIXM which outperforms the S\&P in 51.04\% of the weeks evaluated. However, this achievement is not repeated when the holding period is one-day or one-month. In fact, the number of successful months for the VIXM declines to a low level of $29.17 \%$. 
The IP performance shows only a slight improvement when compared to the appropriate core portfolio, i.e. Core st $_{\text {or }}$ Core $_{\text {md. }}$. For example, the UVXY outperforms the S\&P in $48.45 \%$ of the days studied while the Core st $_{\text {does }}$ so in $48.26 \%$. Similarly, the TVIZ, VIXM and VIXY outperform the S\&P with greater frequency than does the Core $_{\text {st }}$ or Core $_{\mathrm{md}}$ when the holding period is one week. Finally, the VIIX outperforms the S\&P in $36 \%$ of the months studied

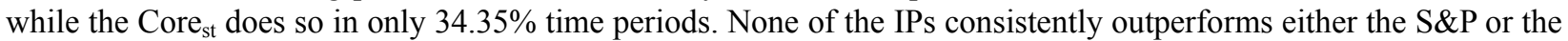
core across all three holding periods. In addition, those IPs which perform well relative to the core under one holding period, tend to generate especially weak outcomes under other holding periods.

The IP performance is noticeably unstable when compared to the null strategy. The one-month fractions indicate very poor IP performance with none of the funds outperforming the S\&P more frequently than the null. However, almost all the IPs are more successful than the null when the holding period is one week but only four when the holding period is one-day.

Table 3. Test 2, comparing the ARAR for each fund to the ARAR for each benchmark, is applied to individual portfolios

\begin{tabular}{|c|c|c|c|c|c|c|}
\hline 1 & 2 & 3 & 4 & 5 & 6 & 7 \\
\hline Fund & $\begin{array}{c}\text { ARAR } \\
\text { Day }\end{array}$ & $\begin{array}{c}\text { ARAR } \\
\text { S\&P } 500 \\
\text { Day }\end{array}$ & $\begin{array}{c}\text { ARAR } \\
\text { Week }\end{array}$ & $\begin{array}{c}\text { ARAR } \\
\text { S\&P } 500 \\
\text { Week }\end{array}$ & $\begin{array}{l}\text { ARAR } \\
\text { Month }\end{array}$ & $\begin{array}{c}\text { ARAR } \\
\text { S\&P } 500 \\
\text { Month }\end{array}$ \\
\hline $\mathrm{CVOL}^{* *}$ & -0.0908 & 0.0382 & -0.5143 & 0.2412 & -2.4157 & 1.8493 \\
\hline TVIX $^{*}$ & 0.3096 & 0.0382 & -0.6047 & 0.2412 & -2.2597 & 1.8493 \\
\hline TVIZ $^{* *}$ & -0.1185 & 0.0382 & -0.6532 & 0.2412 & -2.5838 & 1.8493 \\
\hline $\mathrm{UVXY}^{*}$ & 0.5032 & 0.0652 & -0.3788 & 0.3546 & -1.8642 & 2.1220 \\
\hline VIIX & -0.0730 & 0.0382 & -0.4687 & 0.2412 & -2.2269 & 1.8493 \\
\hline VIIZ $^{* *}$ & -0.1139 & 0.0382 & -0.5518 & 0.2412 & -2.3473 & 1.8493 \\
\hline VIXM $^{* *}$ & -0.0887 & 0.0222 & -0.1433 & -0.0443 & -2.2658 & 1.1318 \\
\hline VIXY* $^{*}$ & -0.0618 & 0.0222 & -0.0690 & -0.0443 & -1.7760 & 1.1318 \\
\hline VXX $^{*}$ & 0.0594 & 0.0725 & -0.6537 & 0.3510 & -2.7059 & 1.4372 \\
\hline $\mathrm{VXZ}^{* *}$ & -0.0916 & 0.0725 & -0.5101 & 0.3510 & -2.2282 & 1.4372 \\
\hline $\mathrm{XVIX}^{*}$ & -0.0737 & 0.0382 & -0.3519 & 0.2412 & -1.0779 & 1.8493 \\
\hline $\mathrm{XVZ}$ & -0.1356 & 0.0598 & -0.6504 & 0.2960 & -2.6535 & 1.8030 \\
\hline Average & 0.0021 & 0.0453 & -0.4625 & 0.2259 & -2.2004 & 1.6799 \\
\hline Core $_{\text {st }}{ }^{*}$ & 0.0076 & & 0.0337 & & -0.0346 & \\
\hline Core $_{\mathrm{md}}{ }^{* *}$ & 0.0003 & & 0.0281 & & -0.0569 & \\
\hline Null & 0.0000 & & 0.0000 & & 0.0000 & \\
\hline
\end{tabular}

*Average VIX maturity is 1-2 months

**Average VIX maturity is 3-4 months

The second performance test examines the ARAR over each holding period to determine if the magnitude of the IP gain is sufficient to outperform the three benchmarks. As such, Table 3 is constructed by averaging the RARs in each time period for the IPs, S\&P, core portfolios and the null strategy. Columns 3, 5 and 7 show the ARARs for the S\&P 500 for a one-day, one-week and one-month holding period, respectively. Likewise, columns 2, 4 and 6 sort the ARARs for each IP for the three holding periods.

The one-day ARARs identify the TVIX and UVXY as having a higher average than all three benchmarks. However, when the holding period is extended to one-week and one-month the results are not repeated. Similarly, the daily ARAR for VXX is greater than the core and the null, but less than the S\&P 500. Once again, this performance is not repeated when the holding period is extended. All other IPs produce ARARs less than the S\&P and the core across all holding periods. Perhaps the most telling conclusion is that the null is a superior strategy to the IPs. 
To summarize, the results of the first test indicate that in the majority of days, weeks and months evaluated the $\mathrm{F}_{\mathrm{sp}, \mathrm{r}}>\mathrm{F}_{\mathrm{i}, \mathrm{r}}$. Likewise, the second test reveals that when the holding period is one-week and one-month the ARAR for all three benchmarks is greater than the ARAR for the IPs. Three IPs are noted exceptions when the holding period is one-day but those funds are among the worst performers when the holding period is lengthened.

Table 4 repeats Test 1, an assessment of the fraction of successful time periods relative to the S\&P 500, using the CPs as the basis for comparison to the benchmarks. The portfolios are constructed by inputting the appropriate fund and S\&P risk-return parameters into equations (2) and (3). The parameters are first weighted using the UC-weighting method, identified in equation (9). The tests are then repeated using weights identified by the WNB in equation (7). It is expected that the CPs will perform better than the IPs due to the strong negative correlation between the fund and the S\&P returns.

Columns 2, 3 and 4 of Table 4 display the fraction of time for which each UC-weighted CP produces RARs greater than the RARs of the S\&P 500 evaluated over one-day, one-week and one-month holding periods, respectively. Similarly, columns 6, 7 and 8 identify the proportion of time when each WNB-weighted CP generates RARs greater than the RARs of the S\&P. Columns 5 and 9 display the average UC and WNB weights, respectively, across three holding periods for each CP.

Table 4. Test 1, measuring the fraction of time periods when the RARs for each fund exceeds the S\&P 500, is applied to constructed portfolios

\begin{tabular}{|c|c|c|c|c|c|c|c|c|}
\hline \multirow[b]{2}{*}{1} & \multicolumn{4}{|c|}{$\mathbf{U C}$} & \multicolumn{4}{|c|}{ WNB } \\
\hline & 2 & 3 & 4 & 5 & 6 & 7 & 8 & 9 \\
\hline Portfolio & F(Day) & F(Week) & F(Month) & $\mathbf{W}_{\mathrm{UC}}$ & F(Day) & F(Week) & F(Month) & $\mathbf{W}_{\text {WNB }}$ \\
\hline $\mathrm{CVOL}_{\mathrm{cp}}{ }^{* *}$ & 0.4494 & 0.3861 & 0.2800 & 0.1625 & 0.4544 & 0.3762 & 0.3200 & 0.1467 \\
\hline TVIX $_{\mathrm{cp}}{ }^{*}$ & 0.4369 & 0.3500 & 0.3333 & 0.1503 & 0.4524 & 0.3663 & 0.3200 & 0.1117 \\
\hline TVIZ $_{\mathrm{cp}}{ }^{* *}$ & 0.4345 & 0.3465 & 0.1600 & 0.1234 & 0.4325 & 0.3861 & 0.2000 & 0.1724 \\
\hline $\mathrm{UVXY}_{\mathrm{cp}}{ }^{*}$ & 0.4810 & 0.4237 & 0.0714 & 0.1375 & 0.4158 & 0.3559 & 0.2857 & 0.0553 \\
\hline VIIX $_{\mathrm{cp}}{ }^{*}$ & 0.4447 & 0.3762 & 0.3002 & 0.2672 & 0.4563 & 0.4257 & 0.3600 & 0.1998 \\
\hline $\mathrm{VIIZ}_{\mathrm{cp}}{ }^{* *}$ & 0.4480 & 0.4100 & 0.2100 & 0.4214 & 0.4611 & 0.4400 & 0.3200 & 0.1815 \\
\hline $\operatorname{VIXM}_{\mathrm{cp}}{ }^{* *}$ & 0.4354 & 0.4375 & 0.3913 & 0.0892 & 0.4188 & 0.4375 & 0.4348 & 0.3074 \\
\hline $\mathrm{VIXY}_{\mathrm{cp}}{ }^{*}$ & 0.4625 & 0.4792 & 0.2609 & 0.1339 & 0.4687 & 0.4062 & 0.2608 & 0.1752 \\
\hline $\mathrm{VXX}_{\mathrm{cp}}{ }^{*}$ & 0.4399 & 0.3731 & 0.2766 & 0.1144 & 0.4497 & 0.4145 & 0.3517 & 0.2601 \\
\hline $\mathrm{VXZ}_{\mathrm{cp}}{ }^{* *}$ & 0.4535 & 0.4255 & 0.2341 & 0.0855 & 0.4608 & 0.4415 & 0.4043 & 0.2413 \\
\hline $\mathrm{XVIX}_{\mathrm{cp}}{ }^{*}$ & 0.4771 & 0.4500 & 0.4400 & 0.0145 & 0.4911 & 0.4752 & 0.4800 & 0.3006 \\
\hline $\mathrm{XVZ}_{\mathrm{cp}}{ }^{*, * *}$ & 0.4644 & 0.4000 & 0.1875 & 0.0333 & 0.4613 & 0.4000 & 0.4375 & 0.0273 \\
\hline Average & 0.4523 & 0.4048 & 0.2638 & 0.1444 & 0.4519 & 0.4104 & 0.3479 & 0.2350 \\
\hline Base $_{\text {st }}{ }^{*}$ & 0.4891 & 0.4427 & 0.3043 & 0.2179 & 0.5467 & 0.5361 & 0.5652 & 0.1187 \\
\hline Base $_{\mathbf{m d}}{ }^{* *}$ & 0.4602 & 0.4389 & 0.3603 & 0.2291 & 0.4682 & 0.5103 & 0.5224 & 0.1378 \\
\hline Null & 0.4451 & 0.3886 & 0.3617 & 0.0000 & 0.4451 & 0.3886 & 0.3617 & 0.0000 \\
\hline \multicolumn{9}{|c|}{ *Average VIX maturity is $1-2$ months } \\
\hline & & & & & & & & \\
\hline
\end{tabular}

In spite of the strong negative correlation between the S\&P 500 and IP returns, none of the CPs produce higher RARs more frequently than the $\mathrm{S} \& \mathrm{P} 500$, i.e. $\mathrm{F}_{\mathrm{pi}, \mathrm{T}}<\mathrm{F}_{\mathrm{sp}, \mathrm{r}}$, regardless of the holding period or the weighting method employed. Even so, the Base $_{\text {st }}$ generates a larger fraction of periods for which the RARs of the short-term maturity base is greater than the S\&P 500, i.e. $\mathrm{F}_{\mathrm{st}, \mathrm{r}}>\mathrm{F}_{\mathrm{sp}, \mathrm{r}}$, for all holding periods, but only when the WNB weights are applied. Likewise, the Base $_{\mathrm{md}}$ results in a larger fraction of time periods for which the RARs of the mid-term maturity base is greater than the S\&P 500, i.e. $F_{m d, T}>F_{s p, T}$, but only when the holding period is one-week or one-month and the WNB weights are applied. It follows that none of the CPs outperform the base when weighted by the WNB approach. However, in 


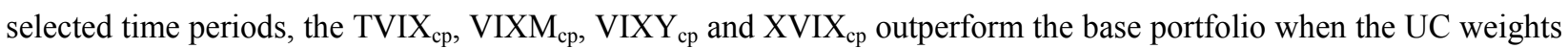
are applied.

The comparison of the $\mathrm{F}_{\mathrm{p}, \mathrm{T}}$ to the null strategy introduces two interesting observations. First, only $33 \%$ or $17 \%$ of the CPs, depending on the weighting method, outperform the null when the holding period is one-month. Similarly, 33\% and $42 \%$ of the CPs outperform the null when the holding periods are one-day and one-week, respectively. Second, the IPs more frequently outperform the null than do the CPs.

Finally, comparing the findings in Table 2 with those in Table 4 reveals an unexpected result: the fraction of successful time periods associated with the IPs is often greater than the CPs.

Table 5 exhibits the results of Test 2 applied to the CPs, the S\&P 500, the base portfolios and the null strategy for each holding period and weighting method. Four UC-weighted and three WNB-weighted portfolios produce daily ARARs greater than the $\mathrm{ARAR}_{\mathrm{sp}}$, indicated by the boxed numbers, but only two portfolios do so when the holding period is one-week or one-month. None of the portfolios consistently outperforms the S\&P across all holding periods or both weighting methods.

The performance of the CPs relative to the $\mathrm{S} \& \mathrm{P}$ is weak but it is even less desirable when compared to the base portfolios. Only one UC-weighted portfolio produces an ARAR greater than the ARAR of the base in each time period. Similarly, one, zero and two WNB-weighted portfolios outperform the base under the one-day, one-week and one-month holding periods, respectively.

The base portfolios generate daily and weekly ARARs greater than the $\mathrm{ARAR}_{\mathrm{sp}}$, under both weighting methods. However, when the holding period is one-month only the ARAR of Base ${ }_{\mathrm{st}}$ is greater than the $\mathrm{ARAR}_{\mathrm{sp}}$. As such, it is not surprising that fewer CPs perform well relative to their respective base portfolio.

Table 5. Test 2, comparing the ARAR for each fund to the ARAR for each benchmark, is applied to constructed portfolios

\begin{tabular}{|c|c|c|c|c|c|c|c|c|c|}
\hline 1 & 2 & 3 & 4 & 5 & 6 & 7 & 8 & 9 & 10 \\
\hline Portfolio & $\begin{array}{c}\text { ARAR } \\
\text { Day }\end{array}$ & $\begin{array}{c}\text { ARAR } \\
\text { Week }\end{array}$ & $\begin{array}{l}\text { ARAR } \\
\text { Month } \\
\end{array}$ & $\begin{array}{c}\text { ARAR } \\
\text { Day }\end{array}$ & $\begin{array}{c}\text { ARAR } \\
\text { Week }\end{array}$ & $\begin{array}{l}\text { ARAR } \\
\text { Month } \\
\end{array}$ & $\begin{array}{c}\text { ARAR } \\
\text { Day }\end{array}$ & $\begin{array}{c}\text { ARAR } \\
\text { Week }\end{array}$ & $\begin{array}{l}\text { ARAR } \\
\text { Month } \\
\end{array}$ \\
\hline & \multicolumn{3}{|c|}{$\mathbf{U C}$} & \multicolumn{3}{|c|}{ S\&P 500} & \multicolumn{3}{|c|}{ WNB } \\
\hline $\mathrm{CVOL}_{\mathrm{cp}}{ }^{* *}$ & 0.1397 & 0.5197 & 1.3246 & 0.0382 & 0.2412 & 1.8493 & 0.0381 & 0.2406 & 1.2850 \\
\hline TVIX $_{\mathrm{cp}}^{*}$ & 0.0158 & 0.3805 & 1.9405 & 0.0382 & 0.2412 & 1.8493 & 0.0403 & 0.2325 & 1.2903 \\
\hline TVIZ $_{\mathrm{cp}}{ }^{* *}$ & -0.0279 & -0.0165 & -0.4414 & 0.0382 & 0.2412 & 1.8493 & 0.0369 & 0.2353 & 1.2899 \\
\hline $\mathrm{UVXY}_{\mathrm{cp}}{ }^{*}$ & 0.0742 & 0.3506 & 0.6756 & 0.0652 & 0.3546 & 2.1220 & 0.0762 & 0.3826 & 2.0015 \\
\hline VIIX $_{\mathrm{cp}}{ }^{*}$ & 0.0570 & 0.1834 & 0.9876 & 0.0382 & 0.2412 & 1.8493 & 0.0372 & 0.2343 & 1.8463 \\
\hline VIIZ $_{\mathrm{cp}}{ }^{* *}$ & -0.0313 & 0.0686 & -0.1014 & 0.0382 & 0.2412 & 1.8493 & 0.0102 & 0.1188 & 0.5583 \\
\hline VIXM $_{\mathrm{cp}}{ }^{* *}$ & 0.0097 & -0.0954 & -0.0896 & 0.0222 & -0.0443 & 1.1318 & -0.0249 & -0.0458 & -0.0660 \\
\hline $\operatorname{VIXY}_{\mathrm{cp}}{ }^{*}$ & 0.0097 & -0.1101 & 0.6499 & 0.0222 & -0.0443 & 1.1318 & 0.0220 & -0.1216 & 1.0098 \\
\hline $\mathrm{VXX}_{\mathrm{cp}}{ }^{*}$ & 0.2987 & 0.3329 & 1.6016 & 0.0725 & 0.3510 & 1.4372 & 0.1680 & -0.6624 & 1.7243 \\
\hline $\mathrm{VXZ}_{\mathrm{cp}}{ }^{* *}$ & 0.0549 & 0.2775 & 0.3466 & 0.0725 & 0.3510 & 1.4372 & -0.0046 & 0.3794 & 2.1107 \\
\hline $\mathrm{XVIX}_{\mathrm{cp}}{ }^{*}$ & 0.0375 & -0.0847 & 0.1123 & 0.0382 & 0.2412 & 1.8493 & -0.0097 & -0.0272 & 0.1269 \\
\hline $\mathrm{XVZ}_{\mathrm{cp}}{ }^{*, * *}$ & 0.0391 & 0.0436 & 0.8413 & 0.0598 & 0.2960 & 1.8030 & 0.0591 & 0.2804 & 1.6414 \\
\hline Average & 0.0981 & 0.1542 & 0.6540 & 0.0453 & 0.2259 & 1.6799 & 0.0374 & 0.1039 & 1.3499 \\
\hline Base $_{\text {st }}{ }^{*}$ & 0.1351 & 0.4352 & 1.7410 & & & & 0.1137 & 0.5352 & 1.9214 \\
\hline Base $_{\mathbf{m d}}{ }^{* *}$ & 0.2593 & 0.3982 & 0.9331 & & & & 0.1579 & 0.4722 & 1.3213 \\
\hline Null & 0.0000 & 0.0000 & 0.0000 & & & & 0.0000 & 0.0000 & 0.0000 \\
\hline
\end{tabular}


The CPs clearly outperform the IPs when performance is compared to the null strategy. Between eight and eleven portfolios generate RARs greater than the null strategy, depending on the holding period and weighting method. No discernible performance differences are observed between the alternate weighting methods or time frames.

In summary, comparing Table 3 with Table 5 confirms that the ARAR of each CP is regularly, but not always, greater than the corresponding ARAR for the IP. Even though the CPs provide a noticeable improvement relative to the IPs, there are also clear inconsistencies in their performance. Minor changes in the portfolio weighting or the holding period can reverse the conclusion and even the relative relationships. The positive outcomes for the base portfolios, indicate that a direct investment in VIX futures is likely to yield superior RARs compared to an indirect investment via volatility ETNs.

\section{Conclusion}

This research applied two tests to determine the performance of twenty-four volatility ETN portfolios compared to three benchmarks: the S\&P 500, a base portfolio and a null strategy. The two tests were composed along three dimensions: portfolio construction, time sensitivity and portfolio weighting methods. Test 1 measured the fraction of time periods for which the RARs for each IP and CP exceeded that of the S\&P. The second test determined the ARAR over each time period for all IPs and CPs to determine superior performance relative to the benchmarks.

The three dimensions examined lead to the following general conclusions:

Portfolio Construction. The first dimension is summarized in Figure 1 by holding constant the effects of the different holding periods and weighting methods. Two conclusions emerge from the test results. First, the results of Test 1 indicate very little difference between the performance of the IPs and CPs as shown by a comparison of F(IP) and $\mathrm{F}(\mathrm{CP})$. Test 2 identifies the CPs as superior to the IPs when compared to the S\&P and the null but compared to the base the two are virtually indistinguishable.

Second, when the core portfolio performance is compared to the base portfolio performance there is clear and unambiguous superiority of the base relative to the core. This is the expected result given the strong negative correlation between the S\&P and VIX futures returns, which implies that the poor CP performance relative to the $\mathrm{S} \& \mathrm{P}$ is unique to the ETNs and not to volatility in general.

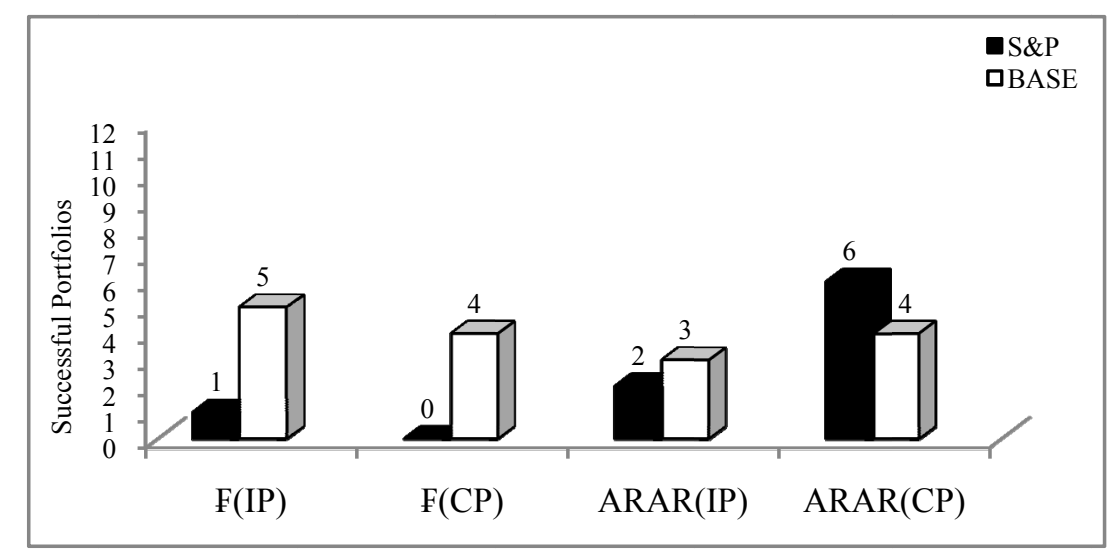

Figure 1. First Dimension Summary Portfolio Construction

Time Sensitivity. The second dimension is summarized in Figure 2 by holding constant the effects of portfolio construction and weighting. Changes in the holding period fail to produce significantly different results with respect to the S\&P500 and the base, regardless of the test applied. It is noteworthy that the successful portfolio results are not robust across time. That is, changes in the holding period may not change the number of successful portfolios but it changes the identity of those prevailing. 


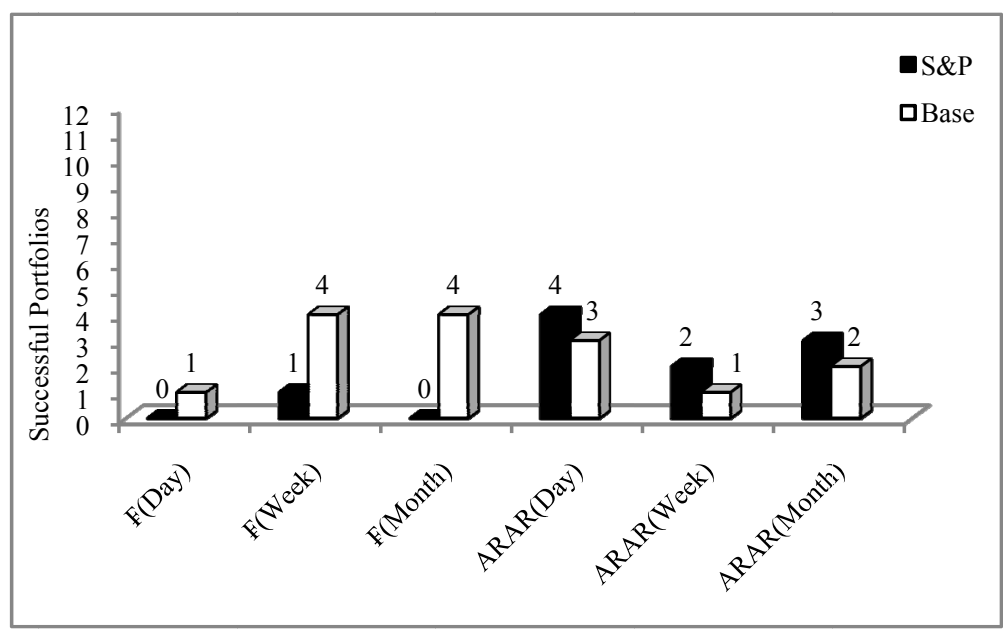

Figure 2. Second Dimension Summary Time Sensitivity

The low number of successful portfolios, across all holding periods and both tests, suggests that changes in the holding period will not improve the performance of volatility ETN portfolios relative to an S\&P 500-only strategy or a direct investment in a VIX futures constructed portfolio.

Portfolio Weighting. The third dimension applies only to CPs and is summarized in Figure 3 by holding constant the effects of different holding periods. The evidence suggests that the UC-weights produce more successful CPs relative to the base but the WNB-weights do so with respect to the S\&P 500. In general, the number of successful portfolios is low under both weighting methods, but more important is the inconclusive nature of the successes. For example, a successful CP under the UC-weighting method is likely to prove unsuccessful when the WNB-weights are applied indicating that even minor changes in weighting can reverse the conclusions.

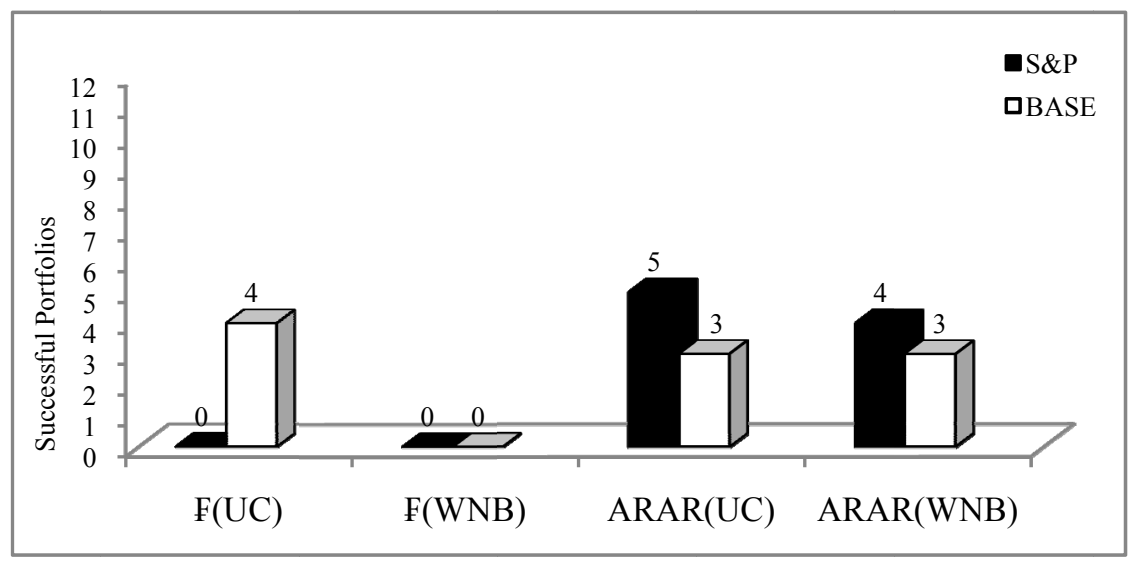

Figure 3. Third Dimension Summary Portfolio Weights

The inferior portfolio results leads to the general conclusion that the risk-adjusted returns of volatility ETNs and ETFs are not sufficient to compensate for the additional risk and higher expenses. Further, the performance cannot be improved with changes in portfolio construction, holding period or weighting methodology. In fact, volatility investors can do better by constructing portfolios directly with VIX futures.

\section{References}

Alexander, Carol \& Dimitris Korovilas. (2012). Diversification of Equity with VIX Futures: Personal Views and Skewness Preference. Social Sciences Research Network. [Online] Available: http://papers.ssrn.com/sol3/papers.cfm?abstract_id=2027580 
Daigler, R., \& L. Rossi. (2006). A Portfolio of Stocks and Volatility. The Journal of Investing, 99-106. http://dx.doi.org/10.3905/joi.2006.635636

Dash, Srikant \& Mathew Moran. (2005). VIX as a Companion for Hedge Fund Portfolios. Journal of Alternative Investments, (Winter):75-80. http://dx.doi.org/10.3905/jai.2005.608034

Dennis, Patrick, S. Mayhew \& C. Stivers. (2006). Stock Reports, Implied Volatility, Innovations, and the Asymmetric Volatility Phenomenon. Journal of Financial and Quantitative Analysis, 41(2), 381-406. http://dx.doi.org/10.1017/S0022109000002118

Durbin, J. and G.S. Watson. (1951). Testing for Serial Correlation in Least Squares Regression. Biometrika, (38), 159-178.

Engle, Robert \& C. Granger. (1987). Error Correction: Representation, Estimation, and Testing. Econometrica, 55(2), 251-276. http://dx.doi.org/10.2307/1913236

Goldwhite, Paul. (2009). Diversification and Risk Management: What Volatility Tells Us. The Journal of Investing, 18(3), 40-48. http://dx.doi.org/10.3905/JOI.2009.18.3.040

Krein, David \& Jeffrey Fernandez. (2012). Volatility Risk Control. Journal of Index Investing, 3(2), 62-75. [Online] Available: http://www.iijournals.com/toc/jii/3/2.

Liu, Berlinda \& Srikant Dash. (2012). Volatility ETFs and ETNs. The Journal of Trading, 7(1), 43-48. http://dx.doi.org/10.3905/jot.2012.7.1.043

Moran, M.T., \& S. Dash. (2007). VIX Futures and Options: Pricing and Using Volatility Products to Manage Downside Risk and Improve Efficiency in Equity Portfolios. The Journal of Trading, (29), 96-105. http://dx.doi.org/10.3905/jot.2007.688954

Rhodes, Russell. (2011). Trading VIX Derivatives: Trading and Hedging Strategies Using VIX futures, Options and Exchange Traded Notes (Wiley Press, New York, NY).

Wang, Zhiguang \& R. Daigler. (2011). The Performance of VIX Option Pricing Models: Empirical Evidence Beyond Simulation. Journal of Futures Markets, 3(3), 251-281. http://dx.doi.org/10.1002/fut.20466

\section{Notes}

Note 1. Hereafter, the terms 'note' and 'fund' are used interchangeably and both refer to the ETNs and ETFs.

Note 2. Twenty-two trading days is approximately equivalent to one calendar month.

Note 3. $\mathrm{R}_{\mathrm{i}, \mathrm{t}}=\mathrm{R}_{\mathrm{j}, \mathrm{t}}$ when VIX futures is evaluated for inclusion in the base portfolios. 